\title{
Bir Kararsızlığın Analizi: Hemşire miyim Yoksa Tıbbi Laboratuvar Teknikeri mi?
}

\author{
Analysis of a Indecision: Am I Nurse or Medical Laboratory Technician?
}

Ayliz VELİĞLU ÖĞÜNÇ, Hülya GÜÇLÜ, Meral YÜKSEL

ÖZ

Sağlık Meslek Liselerinden (SML) mezun olan öğrencilere sınavsız geçiş hakkı tanınması ile 2006-2009 yılları arasında, M.Ü Sağlık hizmetleri Meslek Yüksekokulu, Tıbbi Laboratuvar Teknikleri (TLT) programına kayıt yaptıran öğrencilerin çoğunluğunu Hemşirelik bölümü mezunları oluşturmuştur. Tibbi Laboratuvar Bölümü (TBL) dışındaki bölümlerden gelen öğrencilerde, mesleki eğitim alt yapısının ciddi bir fark yaratmayacağı düşünülse de önemli sorunlarla karşılaşılmıştır.

Sorunların en başında, kamu hastanelerine hemşire olarak atanmış, yoğun tempoda çalışan öğrencilerimizin durumu gelmiştir. Özellikle tıbbi laboratuvar teknikerinin temel becerileri için belirgin yetersizlikleri olan hemşirelik çıkışlı öğrencilerimizin, eksiklerini tamamlama gayretleri olsa da, bunun için enerjileri ve zamanları kalmamıştır.

Çalışmamızda, TLT programına kayıt yaptıran Hemşirelik bölümü öğrencileri ile ilgili görünür sorunları irdelemek ve göremediklerimizi ortaya çıkarmak amacıyla anket çalışması yapılmıştır. Diğer bir amacımız da öğrencilerimizin "karasızlık analizlerini” yaparak, mesleki kariyerleri için kendilerine faydalı bir yönlendirmede bulunabilmektir.

2007-2009 eğitim öğretim yıllarında TLT programımıza kayıtlı, 71'i SML Hemşirelik bölümü mezunu, toplam 87 öğrenciye uygulanan anket sonucunda, öğrencilerin \%40,2'sinin hemşire olarak çalıştığı ve \% 57,5'nin KPSS sınavı ile "Hemşire" olarak atanmak istediği belirlenmiştir. Ortaya çıkan çelişkili durum ise öğrencilerin üniversite mezuniyetleri sonrasında, "Tıbbi Laboratuvar Teknikeri” olarak çalışmayı tercih edeceklerini bildirmeleri $(\% 82,8)$ ve meslek tanımı olarak "Tıbbi Laboratuvar Teknikerliğini "seçmeleri $(\% 59,8)$ olmuştur.

Sonuç olarak, Hemşirelik Bölümünden mezun öğrencilerin, bilinçli olmayan bir tercihle TLT programına devam ettikleri; mesleki tercihlerindeki karasızlığın sürdüğü belirlenmiştir.

Anahtar kelimeler: Tıbbi Laboratuvar Teknikeri, Hemşire, Sınavsız Geçiş

Ayliz VELİOĞLU ÖĞÜNÇ (四), Hülya GÜÇLÜ, Meral YÜKSEL

Marmara Üniversitesi, Sağllk Hizmetleri Meslek Yüksekokulu, Haydarpaşa Kampüsü, Üsküdar/ISTANBUL

e-mail:avogunc@marmara.edu.tr

\begin{abstract}
The majority of the students enrolled in the M.U Vocational School of Health Related Professions, Medical Laboratory Techniques (MLT) program were graduated from Nursing Department between the years 2006-2009 with the granting of the right of passing without examination to the students graduated from Health Vocational High Schools (HVS). Although the vocational education infrastructure of students from departments outside the Medical Laboratory Department (MLD) is not seen as a serious problem, it has encountered significant problems. At the beginning of the problems, assigned as a nurse in public hospitals it has become busy schedule working conditions of our students. Especially they have apparent lack of basic skills for laboratory training, but have not enough time to develop their lacking skills.

In our study, a questionnaire study was conducted in order to investigate visible problems related to the students of the Nursing Department enrolled in the MLT program and to reveal what we cannot see. Our another aim, making a useful guidance for their professional carrier and choices. In the academic year 2007-2009, according results of our survey, that it applied to 87 students (71 nurse) from MLP, 40, 2\% of students worked as nurse, 57, 5\% want to be assigned by KPSS exam as nurse. And we determined a dilemma, which the nursing graduate students, they would prefer to work as medical laboratory technician $(82,8 \%)$ and after their graduation will define themselves as "Medical Laboratory Technician" (59.8\%).

In conclusion, the students who graduated from the Nursing Department continue their TLT program with an unintentional preference; It has been determined that unfairness in professional preferences continues.
\end{abstract}

Keywords: Medical Laboratory Technician, Nurse, Passing Without Exam

\section{GíRiş}

Sınavsız geçiş; 2002 yılından itibaren uygulanan, mesleki ve teknik ortaöğretim kurumlarından mezun öğrencilerin, bitirdikleri bölümün devamı niteliğindeki meslek yüksekokulu ön lisans programlarına sınavsız yerleştirildiği uygulamadır. 
Sağlık Meslek Liselerinden, Sağlık Hizmetleri Meslek Yüksek Okulları'na (SHMYO), sınavsız öğrenci kabulünün ilk üç y1lında (2002-2005), yüksekokulumuzun TLT programına kayıt yaptıran öğrencilerin çoğunluğunu, SML Tıbbi Laboratuvar Bölümü mezunları oluşturmuştur. Ön lisans programları arasında Hemşirelik programının kapatılması sonucunda, 2006-2009 yıllarında, programımız hemşirelik mezunlarınca yoğun ilgi görmüş ve tercih edilmiştir. Dışarıdan bakıldığında bu durumun mesleki eğitim alt yapısı açısından ciddi bir fark yaratmayacağı düşünülse de önemli sorunlarla karşılaşılmıştır.

Sorunların en başında, kamu hastanelerine hemşire olarak atamaları yapılmış, ayda 10-12 nöbeti olan ve çok yoğun bölümlerde hemşire olarak çalışan öğrencilerimizin durumu gelmektedir. Bu öğrencilerimiz, sürekli uykusuz, yorgun, çoğu zaman moralsiz halde derslere katılmak zorunda kalırken, devamsızlık oranı da buna bağlı olarak artmıştır. Özellikle uygulamalı derslerde, laboratuvar çalışmasındaki yetersizlikleri belirginleşen hemşirelik çıkışlı öğrencilerimizin, eksiklerini tamamlama gayretleri olsa da, bu gayrete ayıracakları yeterli öğrenme enerjileri kalmamıştır. Diğer büyük sorun da, hemşire olarak meslek hayatlarına başlamış olan öğrencilerimizin, mezuniyet sonrası Tıbbi Laboratuvar Teknikeri olarak çalışmayacak olmaları, üniversite diplomalarını hemşirelik kariyerinde avantaj olarak kullanmayı amaçlamalarıdır.

Çalışmamızda, konu üzerindeki görünür sorunları irdelemek ve göremediklerimizi ortaya çıkarmak amacıyla bir anket çalışması yapıldı. Diğer bir amacımız da, mevcut sorunların çözümlenmesi için ipuçları bulmak ve öğrencilerimizin " karasızlık analizlerini” yaparak, mesleki kariyerleri için kendilerine faydalı bir yönlendirmede bulunabilmekti.

\section{YÖNTEM}

2007-2009 eğitim öğretim yıllarında Marmara Üniversitesi SHMYO TLT 1.ve 2. Sinıfında öğrenim gören, toplam 87 öğrenciye 22 soruluk bir anket uygulandı. Anket sorularında öğrencilerin mesleki tercihleri üzerine düşünceleri irdelendi. Sorulara verilen yanıtlar yüzdelik oran olarak hesaplandı ve yorumland1.

\section{BULGULAR}

Ankete katılan 87 öğrencinin 71'i SML Hemşirelik, 15'i SML Tıbbi Laboratuvar, 1'i SML Sağlık Memurluğu bölümü mezunu idi. $\mathrm{Bu}$ öğrencilerin mezun oldukları okulların İstanbul, Ankara, Mardin, Bilecik, Samsun, Kırıkale, Kocaeli, Elazığ, Rize, Giresun, Bayburt, Malatya, Çorum, Erzincan ve Canakkale illerinde bulunduğu belirlendi. Öğrencilerin liseden mezun olma notları 5'lik sistem üzerinden 3,00-4,98 arasındaydı. Öğrencilere yönelttiğgimiz sorular ve yanıtları Tablo-1 ve Tablo-2'de görülmektedir.

Tablo 1: Öğrencilerin sorulara verdiği Evet/Hayır cevaplarının oranı (n:87)

\begin{tabular}{|c|c|c|c|}
\hline SORULAR & EVET $(\%)$ & HAYIR (\%) & BOŞ (\%) \\
\hline Lise mezuniyeti sonrası "hemşire" olarak çalışıyor musunuz? & $35(40,2)$ & $52(59,8)$ & 0 \\
\hline Eğitiminize başladığınızda çalışıyorken sonradan eğitiminiz için işinizi bıraktınız mı? & $21(24)$ & $64(73,6)$ & $2(2,3)$ \\
\hline Hem çalışıp hem okuyorsanız ailenizin yanında mı kalıyorsunuz? & $47(54,1)$ & $29(33,3)$ & $11(12,6)$ \\
\hline Üniversite eğitimi sırasında KPSS sınavı ile "hemşire" olarak bir kuruma atanmayı düşünüyor musunuz? & $50(57,5)$ & $33(37,9)$ & $4(4,6)$ \\
\hline Üniversite eğitimi sonras1 “Tibbi Laboratuvar Teknikeri” olarak mesleğinizi yapacak mısınız? & $72(82,8)$ & $8(9,2)$ & $7(8,0)$ \\
\hline Derslerinize düzenli olarak katılıp verim alabiliyor musunuz? & $71(81,6)$ & $15(17,2)$ & $1(1,2)$ \\
\hline Ailenize ekonomik destek sağlamak zorunda mısınız? & $49(56,3)$ & $37(42,5)$ & $1(1,2)$ \\
\hline Çalışmadan okuyorsanız herhangi bir ekonomik destek olanağınız var mı? & $25(28,7)$ & $43(49,4)$ & $19(21,9)$ \\
\hline "Hemşire” olarak çalışıp "Tıbbi Laboratuvar Programı” okumaktan memnun musunuz? & $61(70,1)$ & $5(5,8)$ & $21(24,1)$ \\
\hline Çalışıorsanız, çalışarak "Tıbbi Laboratuvar Programı” okumanın mesleki faydasına inanıyor musunuz? & $59(67,8)$ & $8(9,2)$ & $20(23,0)$ \\
\hline Derslerinize düzenli olarak katılıp verim alabiliyor musunuz? & $77(88,5)$ & $9(10,3)$ & $1(1,2)$ \\
\hline Çalışıyorsanız sağlık sorunu yaşıyor musunuz? & $14(16,1)$ & $58(66,7)$ & $15(17,2)$ \\
\hline $\begin{array}{l}\text { Çalışarak eğitim görüyorsanız özel hayatınıza, ailenize ve diğer isteklerinize (hobi, spor...) zaman } \\
\text { ayırabiliyor musunuz? }\end{array}$ & $37(42,6)$ & $25(28,7)$ & $25(28,7)$ \\
\hline $\begin{array}{l}\text { Çalışarak eğitim alıyorsanız, Tıbbi Laboratuvar Staj Eğitiminden verim aldığınızı/alacağınızı düşünüyor } \\
\text { musunuz? }\end{array}$ & $52(59,8)$ & $6(6,9)$ & $29(33,3)$ \\
\hline Çalıştığınız yerlerde eğitiminize devam edebilmeniz açısından anlayış görüyor musunuz? & $46(52,9)$ & $7(8,0)$ & $34(39,1)$ \\
\hline $\begin{array}{l}\text { Sağlık Meslek Lisesi "Hemşirelik" bölümü mezunu olarak, Sağlı Meslek Lisesi "Tıbbi Laboratuvar" } \\
\text { bölümünden gelen arkadaşlarınıza göre mesleki bilgi yönünden kendinizi yetersiz hissediyor musunuz? }\end{array}$ & $26(29,9)$ & $51(58,6)$ & $10(11,5)$ \\
\hline Üniversitede ders dışı faaliyetlere (Folklor, spor aktiviteleri, konser) katılma imkanınız var mı? & $31(35,6)$ & $53(60,9)$ & $3(3,5)$ \\
\hline Kendinizi üniversite öğrencisi olarak hissediyor musunuz? & $55(63,2)$ & $30(34,5)$ & $2(2,3)$ \\
\hline
\end{tabular}


Tablo 2: Öğrencilerin Hemşirelik/Tıbbi Laboratuvar tercihlerinin oranları (n:87)

\begin{tabular}{|c|c|c|c|}
\hline SORULAR & $\begin{array}{c}\text { Hemşirelik } \\
(\%)\end{array}$ & $\begin{array}{l}\text { Tibbi Laboratuvar } \\
(\%)\end{array}$ & $\begin{array}{c}\text { Diğer } \\
(\%)\end{array}$ \\
\hline $\begin{array}{l}\text { KPSS ile atama nedeniyle eğitiminize ara verme durumunda "hemşirelik" mesleğini mi } \\
\text { yoksa "Tibbi Laboratuvar" eğitimini mi seçersiniz? }\end{array}$ & $25(28,7)$ & $52(59,8)$ & $10(11,5)$ \\
\hline $\begin{array}{l}\text { Üniversite mezuniyetiniz sonrasında mesleğiniz sorulduğunda hangisini meslek tanımınız } \\
\text { olarak seçersiniz? }\end{array}$ & $7(8,0)$ & $52(59,8)$ & $28(32,2)$ \\
\hline $\begin{array}{l}\text { Okul dönemindeki hayatınızda kendiniz için hangi mesleğin sosyoekonomik açıdan daha } \\
\text { avantajlı olduğunu düşünüyorsunuz? }\end{array}$ & $48(55,2)$ & $35(40,2)$ & $4(4,6)$ \\
\hline
\end{tabular}

Tablo-1 ve Tablo-2'de sunulan anket yanıtlarına ve yüzde oranlara göre; SML Hemşirelik bölümünü bitirerek, TLT Programına devam eden öğrencilerin çoğunun çalışarak okuduğu (\%40,2), bu öğrencilerin eğitimleri devam ederken Kamu Personeli Seçme Sınavı (KPSS) ile "Hemşire" olarak atanmak istediği $(\% 57,5)$ belirlendi. Ortaya çıkan çelişkili durum ise öğrencilerin TLT programından mezun olduktan sonra "Tıbbi Laboratuvar Teknikeri” olarak çalışmayı tercih edeceklerini bildirmeleri $(\% 82,8)$ ve üniversite mezuniyeti sonrası meslek tanımı olarak Tıbbi Laboratuvar Teknikerliğini seçmeleri $(\% 59,8)$ oldu.

\section{TARTIŞMA}

Ülkemizde meslek liselerinden meslek yüksekokullarına sınavsız geçiş 2002 yılında çıkarılan 4702 sayılı kanunla yürürlüğe girmiştir. $\mathrm{Bu}$ tarihten günümüze sınavsız geçişin, çeşitli meslek alanlarında faaliyet gösteren meslek yüksekokullarının başarı ortalamalarını düşürdüğü çok sayıda yayınla bildirilmiştir. Nartgün ve arkadaşlarının çalışmasında meslek yüksekokullarına sınavsız geçişte uygulanan koşullar değerlendirilmiş, sınavsız geçiş yapan öğrencilerin ön lisans tercihlerinde ortaöğretimdeki programlarının devamı niteliğindeki programlara kayıt yaptırmalarının doğru olacağı bildirilmiştir (1). Alkan ve arkadaşlarının çalışmalarında, meslek yüksekokullarının en temel sorunlarının başında sınavsız geçişin geldiği, bu uygulamanın meslek yüksekokullarında öğrenci profilini (öğrencinin akademik seviyesi açısından) olumsuz yönde etkilediği bildirilmiştir (2).

Sınavsız geçiş uygulamasının beraberinde getirdiği önemli bir sorun da, SML' nin bazı bölümlerinden, mesleki eğitimde uygun olamayacak ön lisans programlarına geçiş hakkı kazanılmasıdır. Çalışmamızda bu sorunun en belirgin şekilde yaşandığı, ortaöğrenimin hemşirelik bölümlerinden, TLT programına sınavsız geçişle yaşanan sorunları ortaya koymaya çalıştık.
Meslek Yüksekokullarının kuruluş amacı ve tanımı 6111 sayılı yükseköğretim kanununa göre şöyledir: "Belirli mesleklere yönelik nitelikli insan gücü yetiştirmeyi amaçlayan, yılda iki veya üç dönem olmak üzere iki yıllık eğitim ve öğretim sürdüren, ön lisans derecesi veren bir yükseköğretim kurumu". Tanımdan da anlaşıldığı üzere hangi meslek olursa olsun, temel ve değişmez hedef kısa sürede nitelikli, yeterli insan gücü yetiştirmektir. Bizim araştırmamızda değindiğimiz ve sınavsız geçişin olumsuzluğuna yoğunlaşan diğer araştırmaların ortak noktası "nitelikli insan gücü" hedefinden sayısal verilerle görülebilen sapmadır. Altıntaş ve arkadaşlarının 1996-2002 ve 2002-2009 yıllarını kapsayan meslek yüksekokullarının çeşitli programlarının başarı verilerini sınavlı giriş dönemi ve sınavsız giriş dönemine göre karşılaştıran çalışmalarında, oranlar programlara göre değişmekle birlikte, teknik ve sosyal alandaki 15 programın tamamında öğrenci başarısı anlamlı düzeyde düşmüştür (3).

Sınavsız geçiş sürecinin başlaması ile birlikte özellikle SML Hemşirelik mezunları, SHMYO Hemşirelik Bölümlerinin kapatılması nedeniyle kısmen bilinçsiz bir seçimle TLT programlarına geçiş yapmaya başladılar. Hemşirelik bölümü mezunlarının TLT müfredat içeriğine hazırlıklı olmadıkları, laboratuvar uygulamaları için gereken uygulama becerilerine sahip olmadıkları dersleri yürüten akademisyenlerce kısa sürede görülmüştür. Özel ve Kamu kuruluşlarında çalışarak öğrenimlerini sürdürürken, hemşirelik mesleğinin gereği olarak s1k nöbete kalma ve yoğun çalışma sonucu fiziksel/zihinsel tükenmişlik gözlenen öğrencilerimizde tıbbi laboratuvarlarda yürütecekleri yeni meslekleri için öğrenmeye yönelik enerji kalmamıştır. Bu olumsuz sürecin sonucunda mesleğe uyumsuzluğu aşamayan öğrencilerimiz, zorlukla ve vasat ortalamalarla mezun olduktan sonra mesleği yapmama, KPSS ile atanıp hemşirelik alanında yaşamlarına devam etme kararı almışlardır. Ülkemiz adına nitelikli iş gücü hedefinden sapılan, öğrenci ve aileleri için de zaman ve para kaybıyla sonuçlanan bir süreç yaşanmıştır. Bulgularımızda 
da görüldüğü gibi, bu öğrencilerin KPSS ile "Hemşire" olarak atanmayı istediklerini, hemşirelik mesleğinin sosyoekonomik olarak kendileri için daha avantajl1 olacağını, buna karşın mezuniyet sonrası kendilerini Tıbbi Laboratuvar Teknikeri olarak tanıtacaklarını ifade etmişlerdir. Bulgularımız arasında öğrencilerin birbiriyle çelişen ifadeleri dikkat çekicidir ve şunu anlatmaktadır: Öğrenciler ne hemşirelik, ne de tıbbi laboratuvar teknikeri olmak adına berrak bir karar alabilmiş değildir. Özgüven ve hevesle bireysel meslek tercihlerini yapamamışlardır. $\mathrm{Bu}$ nedenle, öğrencilerimizin mesleki kariyerleri ve ülke faydası adına, TLT programına geçiş yapabilecek bölümler arasında hemşirelik olmamalıdır. Direk geçiş hakkı, ortaöğretim tıbbi laboratuvar programı ve diğer laboratuvar programlarıla sinırlı kalmalıdır.

Hemşirelik bölümünden TLT programına geçişteki sorunlar çerçevesinde bulgular paylaştığımız çalışmamızda, sınavsız direk geçişin öğrenci başarısına olan olumsuz etkilerini biz de gözlemledik. Bostan'ın "Sağllk Hizmetleri Mesleki Eğitiminde Sınavsız Geçiş Sorun mu?" başlıklı çalışmasında, sınavla gelen öğrencilerin ortaöğretim not ortalamalarının, sınavsız öğrencilerden yüksek olduğu ve bu farkın ön lisansta ders başarısı ve mezuniyet için belirleyici olduğu vurgulamıştır (4). Karagül ve arkadaşlarının çalışmasında da sınavlı ve sınavsız geçişle gelen öğrencilere eş zamanlı yapılan matematik testi sonucunda, sınavsız geçişle gelen öğrencilere ait skorların anlamlı biçimde düşük olduğu bu temel ders üzerinden görülmüş, sınavsız öğrenci alımı uygulamasının kaldırılması önerilmiştir (5).

Sınavsız geçişle birlikte yaşanan program uyumsuzlukları dışında, Ceylan ve Ekbir' in çalışmasında da belirtildiği gibi, meslek yüksekokullarının eğitim kalitesini etkileyen diğer bir olumsuzluk da, öğrencilerin mesleki gelecekleri için ümitsiz ve yeterli akademik destekten yoksun olmalarıdır (6). Meslek yüksekokullarında görülen akademik kadro ve altyapı eksikleri, öğretim üyelerinden yeterli danışmalık desteği alamama durumu da öğrencileri mesleki motivasyondan uzaklaştırmaktadır $(7,8)$. Aralık 2016'da YÖK' den yapılan açılama ile meslek liselerinden, ön lisans programlarına sınavsız geçiş kaldırıldı. 2017'den itibaren ek puan uygulamasına geçileceği duyuruldu. $\mathrm{Bu}$ düzenlemeyle, tüm MYO' larda artacak öğrenci başarısını ve daha ileride öğrencilerin akademik yeterliğinin, mesleki yetkinliklerine yansımalarını öngörmek mümkündür. Sınavsız geçişin uygulandığı dönemleri kapsayan ve mesleki eğitime yansıyan sonuçlarını inceleyen tüm çalışmalar; meslek yüksekokulu mezunu gençlerin istihdamındaki olumsuzlukların önlenmesi için şüphesiz ki değerli olacaktır. Ayrıca yine bu çalışmalar, sınavsız geçişin kaldırıldığı düzenlemede de görüldüğü gibi, ön lisans eğitiminin revizyonunda doğru hamlelerin yapılmasına önemli katkı sağlayacaktır.

\section{KAYNAKLAR}

1. Nartgün Ş, Yüksel E. Meslek Yüksekokullarına Sınavsız Geçişte İzlenen Kriterlerin Değerlendirilmesi. Abant İzzet Baysal Üniversitesi Dergisi, 2009, 9: 189-205.

2. Alkan R. M, Suiçmez M, Aydınkal M, Şahin M. Meslek Yüksekokullarında Mevcut Durum: Sorunlar ve Bazı Çözüm Önerileri. Yükseköğretim ve Bilim Dergisi, 2014; 4: 133140.

3. Altındaş L, Çelikkol E.S, Tekin V.N, Genç S.Y. Comparing the Success of Students Placed by Examination and through Open Admission To The Vocational Schools. International Journal of Bussiness and Social Science, 2011; 2(8): 71-76.

4. Bostan S. Sağlık Hizmetleri Meslek Eğitiminde Sınavsız Geçiş Sorun mu? Tıp Eğitimi Dünyası, 2007; 24: 23-27.

5. Karagül K, Karagül N, Doğan M. Sınavlı ve Sınavsız Geçiş İçin Akademik Bir Karşılaştırma. II. Uluslar arası, VI. Ulusal Meslek Yüksekokulları Sempozyumu, Aydın, 25 -27 Mayıs 2011; 1:1-5.

6. Ceylan H, Erbir M.A. Meslek Yüksekokullarında Kalite: Mevcut Durum, Sorunlar ve Çözüm Önerileri, Electronic Journal of Vocational Colleges May/May1s 2015: 99-106.

7. Kaya A. Meslek Yüksekokulunda Öğrenim Gören Öğrencilerin Eğitim Öğretim ve Geleceğe Yönelik Düşünceleri. Ondokuz Mayıs Üniversitesi Eğitim Fakültesi Dergisi, 2014; 33(2): 349-356.

8. Kenar N. Türkiye'de Mesleki Eğitimi ve Meslek Yüksekokulları, http://www.messegitim.com.tr/ti/799/0/ TÜRKIYYE'DE MESLEKİ EĞİTIM VE MYO'LAR, Web Dokümanı (Erişim tarihi: 29.03.2016) 